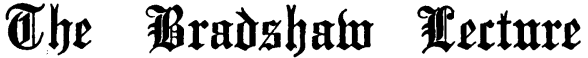

\author{
ov
}

\section{CANCER AND ITS ORIGIN.}

Delivered at the Roy xl Coll sge of Sur jons on Decem 3er 9 th.

BY HENRY MORRIS, M.A., F.R.C.S.

Senior Vice-President and Chairman of the Court of Examiners of the Royal College of Surgeons of England: Senior Surgeon to, and Chairman of the Cancer Investigation Committee of, the Middlesex Hospital.

I HAVE chosen cancer, meaning thereby both carcinoma and sarcoma, as the subject of this lecture for several reasons.

1. The discovery of the microbic origin of certain diseases has led to the most painstaking efforts to ascertain, by means of modern bacteriological methods, the cause, or causes, of cancer. What the result has been $I$ shall endeavour to show.

2. The premature publication of immature and disputable conclusions, and of crude and impossible theories, has unfortunately aroused false hopes, and has attracted the impatient and somewhat ton credulous attention of the general public to everything connected with the word "cancer." It would be well, if it were possible, to allay these consequences.

3 No lecture, especially on cancer, has been given at this Co lege since the last Morton lecture was delivered in May, 1894 .

4. This Royal College has for the first time in its history recently embarked on a great and important scientific inquiry by, conjointly with the Royal College of Physicians, under taking the general direction and control of what may be called a national movement for the investigation of cancer; and it may be of interest to review, although very imperfectly, the general position of the subject at the commencement of this undertaking by the Royal Colleges.

I had thought of prefacing what I have to say to-day on cancer and itsorigin by a short account of the leading views which have been expressed in this country during the last thirty years about cancerous affections. To this end I studied and made epitomes of all the lectures bearing on cancer which have been delivered in this College during that period, as well as of the two great debates on cancer which have taken place within the same period, the one in London in 1874 and the other in Glasgow in 1886.

These lectures and debates contain all that was known about cancer, and of the theories as to its causation, up to the date of their publication; but I found that even the briefest summary of them would extend far beyond the limits of an hour's discourse.

With regard to the theories of causation of malignant diseases which have been published since the delivery of the last of the Morton lectures, even a mere statement of them would occupy much time; and any attempt at a complete account would take up several hours.

Dr. Alexander Katz of Hamburg, in a paper read before the Berlin Cancer Committee in January, 1902, grouped the alleged causes of cancer formation into the entogenous (or intrinsic) and the ectogenous (or extrinsic).

By entogenous causes are understood' certain spontaneous and anomalous changes within the organism; by ectogenous causes those derived from outside the body. The entogenous embrace, amongst many others, the causes alleged nnder the two important theories of Thiersch and Cohnheim. Thiersch's theory, and all the variants of it. may appropriately be called the "lost balance theories" in contradistinction to the "matrix" or "tumour germ" theory of Colnnheim and his followers.

According to Thiersch, the beginning of a tumour formation is due to a loss of balance between the epithelial cells and the connective tissue. In carcinoma, for example, this loss of balance occurs during advancing age by the degeneration of the connective tissue, and results in an invasion of these tissues by the epithelial cells. In other words, the theory supposes that in its origin carcinoma depends on some cause which produces, as age advances, a local impairment of resistance, a retrograde process in the subepithelial structures, whilst the epithelium maintains its activity, or, it may be, acquires a special vigour. This view, Katz says, has never gained a foothold, and is only of value in that by means of it the age limit of cancer can be explained. Katz's state- ment is, however, at variance with the somewhat considerable importance which has been attached to Thiersch's theory, at any rate, in this country, for it was accepted as probable by Coats and Maylard in the Glasgow debate; it was adopted in his Morton lectures by Sims Woodhead, who corroborated it by what he found on microscopic examination of the tongues of old people; in principle it has been quite recenily supported by Foulerton and by Woods Hutchinson; it appears also in the theory of "unstable equilibrium" of Powell White: and its influence is also traceable in certain other modern theories, as, for example, the "anaplastic" theory of Hansemann.

Thiersch's theory, and the other "lost balance theories" are all open to the same objections which the "localists" brought against the "constitutional" theory.

To hold that the formation of carcinoma is due to a loss of the normal balance between the epithelium and the connective tissue, the result of advancing age, is to imply the existence of an "all-pervading condition" of the connective tissues, and yet that this " all-pervading condition" can give rise to a disease which, at its outset at least, is strictly localized. A disease so originating is not less of a constitutional disease than one due to a "special material in the blood"; and suclr a theory of cancer is open to all the same arguments as the "blood theory."

Indeed Paget, after pointing out that there are not many things which do "all pervade the body," fixed upon the "all pervading blood," rather than the "all pervading connective tissue," as the medium of the supposed "virus," merely, as he said, "because at any rate we can then hold to our study by some sort of analogy with things that we recognize as blood diseases." If the theory was correct, cancer should commence, not as a solitary tumour, but as a general carcinomatosis or sarcomatosis.

I must pass now to a brief consideration of the ectogenous group of conjectural causes.

These are (I) the various forms of injury, chronic irritation, and chronic inflammation; and (2) micro-organisms.

Great importance has been attached by Virchow and many others to chronic irritation as a causative factor in cancer; and it is certainly needful for us all to bear in mind the pernicious role played by the clay pipe, the carious tooth, and many and various agencies of the kind in provoking the development of cancer.

But not one of them can take rank as the essential and unconditional cause of malignant disease; that is as the factor without which cancerous diseases cannot arise ; though they are unquestionably amongst the agents which excite the real factor of tumour formation into activity, and as sucle they must be referred to again in connesion with the "tumour germ" theory.

\section{The Microbic Theories.}

The theory of the microbic origin of cancer still occupies the very forefront of cancer research. There are not wanting, however, indications that it is on the wane, and that it may soon come to be described, as indeed Hansemann in his recent work has already spoken of it, as " beIonging to history."

The search for a specific micro-organism of cancer dates back to the early days of modern bacteriolngy. As soon as tuberculosis was removed from the list of diseases due to a so-called diathesis, by the discovery in 1882 of the bacillus tuberculosis, a very large number of scientific workers made it their aim to demonstrate, if possible, the existence of a corresponding micro-organism as the causative agent of carcinoma and sarcoma. Nedopil, in a memoir published in i883 was the first to sustain with conviction the microbic: origin of cancer. No sign of a specific cancer organism had, however, at that time been demonstrated. But research soon led to the alleged discovery by different experimental workers of three classes of living agents, namely, bacteria, protozoa, and saccharomycetes and blastomycetes, or yeast fungi.

\section{The Bacterial or Schizomycetic Theory.}

Bacteria were the first organisms which were thought to be the cause of cancer. Nepveu, as far back as 1872 , liad found them in carcinoma, and Rappin is said to have actually isolated a diplococcus both from epithelioma and sarcoma in 1886. During 1887 there appeared a number of writings by different investigators who claimed to have discovered, eitherin cancerous tumours or in the blood of cancerous persons, the microbe of cancer, and to have isolated and cultivated it, and by means of inoculation of the fluid culture to have obtained the reproduction of the disease in animals.

Scheuerlen claimed to have isolated and cultivated a 
special bacterium from carcinoma. Francke described a bacillus of sarcoma which he differentiated from. the bacterium found by scheuerlen in carcinoma. Schill stated that he had successfully cultivated a bacterium from both carcinoma and sarcoma. Others subsequently made similar claims, whilst, on the other hand, several eminent observers were arliving at the conclusion that many of the supposed micro-organisms were the factitious products of faulty technique, and that such microorcanisms as had been actually discovered played but a very subordinate rôle, if any, in the evolution of malignant tumours.

\section{The Protozoic or Psorospermic Theory.}

Before the year 1884 attention had scarcely at all been directed to the presence of sporozoa in human pathology ; but betiveen that date and 189 I coccidia (a group of parasites belonging to this class of protuzina) were found in a variety of the organs of man, especially in the pleura, the intestinal \&pithelium, the liver, and ureter, as well as in the mucus fiom the air passage of persons suffering from whoopingcough.

In 1889 and the following year a number of descriptions were given by several observers of coccidia-like bodies having a great resemblance to the coccidium of the liver of rabbits which they had discovered in carcinoma of the skin, jaw, intestine, stomach, nipple and breast, prostate and bladder, and other parts. These bodies were found both in the nucleus and protoplasm of cancer cells. In 1891-2 Ruffer found and described bodies which he regarded as psorosperms in the protoplasm of carcinoma cells. In the same and the following years other workers described similar results. In 1901 appeared Schueller's monograph with the description of the round or oval yellowish-grey or yellowishbrown protozoon of cancer, showing radiating striae or cilia in their structure, which he had discovered. In 1901 Gaylord published an account of certain spherical bodies alleged by him to be cancer organisms; and v. Leyden described a protozoal organism in the form of motile cells. In a work just published Dr. Ludwig Feinberg argues for the animal nature of his cancer parasite, to which he gives the name "histosporidium carcinomatosum."

On the other hand, many observers have asserted that all these alleged cancer organisms are not psorosperms, but the products of cell degeneration or cell inclusions of leucocytes or red blood discs, or are the result of irregular forms of indirect division of epithelial cells; and Ribbert brought forward, amongst other objections, his ingenious and telling argument of "symbiosis" against the validity of the microbic origin of cancer.

The Blastomycetic Theory.

The theory that carcinoma is due to infection by a vegetable parasite belonging to the blastomycetes or yeast fungi was first promulgated by Russell in 1890. Russell found certain small round bodies within the cells of carcinoma which retained the fuchsin stain after sections of carcinomatous tumours had been treated with carbol fuchsin, then decolorized with alcohol, and finally counterstained with iodine green. These "fuchsin bodies" he regarded as yeastlike or "sprouting fungi."

Prior to Russell's paper the yeasts had been considered as wanting in any pathogenic effect: but within a few years after cases of yeast infection in man, resulting in the formation of granulomata but not of malignant new growths, came to be recorded.

The blastomycetic theory of the origin of cancer has been since pursued chiefly by Sanfelice and Roncali, who not only confirmed Russell's views, but have gone much further. Plimmer, who was previously a strong supporter of the protnzoic theory. and had, like Soudakewitch, Metchnikoff, Ruffer, and others, described the cancer bodies as protozoa became a convert to the views of Russell, Sanfelice, and Roncali, whilst Sawtschenko, who was also converted, has recently described as representing yeasts the same figures which he had formerly described as representing protozoa.

As in the case of bacteria and psorosperms, so with the yeasts alleged to have been found in cancers, their nature is disputed by many observers. The "fuchsin bodies" of Russell were regarded by Cazin and Duplay as a certain form of cell degeneration (globes hyalines); by Nepveu as being derived from changes in the nuclei of leucocytes, or in red blood corpuscles, or still oftener from the endothelial cells of the lymphatics; and by others they were considered to be due to degeneration of protoplasm, or to atypical mitosis and phagocytosis; whilst Foulerton and Price-Jones pointed out three possible sources of fallacy as to the presence of yeasts in cultures obtained from malignant new growths, the chief of the three being contamination owing to the presence of yeasts or torulae in the air of the laboratory.

In short, neither fission fungus, yeast fungus, nor psorosperm - neither bacterium, blastomycete, nor protozoonhas up to the present moment been satisfactorily shown, in spite of years of patient study by many skilled workers, to $\mathrm{b} \in$ in any sort of causal relationship to these diseases.

How different was the case of the tubercle bacillus! for when Koch announced his great discovery he was able to bring forward such overwhelming proof of the correctness of his claim that, with few exceptions, the most sceptical were forthwith convinced.

The Transmission of Cancer by Grafting and Direct Inoculation. Some of the results of graiting and direct inoculation have often been evoked in support of the microbic theories of cancer genesis, though upon very inadequate grounds. For more than a century experiments have been resorted to with the object of testing :

1. Whether cancer can be transmitted from man to animals, or from one animal to another of a different species.

2. Whether cancer is communicable from man to man, or from one animal to another of the same species.

3. Whether one part of a cancerous individual can be inculated from another part which itself is the seat of cancer.

Clinical observations have also been directed to the solution of some of these questions.

Reference may be made to Cazin $^{2}$ for the earlier, and to Behla's lecture on "cancer à deux" delivered before the Berlin Cancer Committee, April 3rd, I90I, for the most recent information on the second of these questions. Macewen in his speech at the Glasgow debate, and De Bovis ${ }^{2}$ in a recent article have also quoted several cases of the alleged communication of carcinoma from man to man; and my friend and former house-surgeon, Mr. Nash, of Bedford, has collected 5 cases of supposed communication of cancer of the tongue and lip from man to man. Morau's observations seem to prove that cancer was communicated from mice to mice by means of bugs.

Many of the cases in man were instances of what is called "conjugal cancer"; and in these, as well as in the cases other than of the genital organs, the cancer formation was, I consider, excited by chronic or repeated irritation, rather than communicated by the transmission from one person to the other of the carcinoma cells.

Several instances of auto-inoculation were quoted by the speakers in the London and Glasgow debates. Hahn succeeded in grafting carcinoma and Cornil sarcoma from one part of a human being with incurable disease to another part of the same patient's body.

Some experiments by Morau are of great importance, because they were the first which were made in a systematic manner to show the transmissibility of a malignant new growth from one animal to another of the same species. ${ }^{3}$ Quite recently Jensen and Borrel have had successful series of inoculations and graftings in white mice. ${ }^{4}$ Jensen had a series of eight, and Borrel of six successes. Jensen's work has now extended over two and a-half years and includes nineteen generations.

None of the results of the experiments, and none of the clinical cases just alluded to, however, give satisfactory support to the microbic theories; nor do they explain the specific capacity of the cells which enables them to grow and multiply on new soil.

The tumour products of microbic infection are the so-called granulomata formed out of the corpuscular elements of the blood and the proliferation products of pre-existing tissue ; they are the results of a chronic inflammatory process, and all the tumours caused by the same kind of microbe are structurally the same, no matter in what part or organ they originate or develop. Not so the tumours of carcinoma and sarcoma. In endothelioma and spindle-celled sarcoma the cells of the secondary tumours are, as in carcinoma, histologically identical with the cells of the primary neoplasm. It is only in round-celled sarcoma that we cannot be sure whether the cells of the secondary growths are derived from the cells of the primary tumour or from the tissue in which the secondary growths occur. The round-celled sarcoma more closely resembles the chronic inftammatory processes than does spindle-celled sarcoma, and still more so than carcinoma.

The primary tumour of carcinoma varies in structure 
according to its location and to the type of epithelial cell which is normal to the part affected. The secondary tumours are also composed of epithelium which has the same form and the same arrangement as that of the primary tumour; and the secondary tumours have, moreover, all the same delicacy of construction as to stroma, blood vessels, and lymphatics, as well as other points of similarity with the primary tumour. All this was strikingly, if quaintly, put by Moxon at the London cancer debate, when he remarked: "You find that rectum cancer is rectum tissue..... whose structure is that of the Lieberkühn follicles of the mucous membrane of the gut"; and, as to the metastatic growths, you do not "find rectum cancer in the rectum and liver cancer in the liver; but. instead of that, I have repeatedly seen rectum in the liver."

Coats in the Glasgow debate told how the delicate structure of the blood vessels which had led to fatal haemorrhage from a primary growth was repeated in the secondary growths in the form of extensive extravasations of blood throughout the tumours.

Stewart has recorded a case in which growths in the liver and lung secondary to carcinoma of the pancreas, besides having the racemose glandular structure of the primary tumour of the pancreas, had also a chemical resemblance, for upon analysis the secondary growths were proved to contain a high percentage of trypsin.

The definite establishment of these facts has proved that the secondary growths are produced by the migration of cells from the primary sent; that the development of these growths is solely by the multiplication of their own cells, and that there is no transition of the parenchyma of the part invaded into the tissue of the carcinoma. So with reference to sarcoma. The typical sarcomatous tumour element is the connective tissue cell, and the secondary tumours resemble the primary in every respect.

From nothing that we know up to the present time of the action of micro-organisms could the microbic theory throw the least light upon the cases of alleged transplantation and direct inoculation of cancer from one person to another. How can we, on the microbic thenry, explain a glandularcelled carcinoma producing in another person a squamouscelled carcinoma, or a squamous-celled carcinoma of the tor:gue giving rise to a spheroidal-celled carcinoma of the mamma, or to a columnar-celled carcinoma of the stomach or rectum. Such alleged cases are at total variance with what occurs in auto-inoculation, and with all the knowledge we have of the local, regional, and general infection of cancer, as well as with our experience of the action of microbes upon living tissues.

Auto-inoculation is then comparable to, if not identical with, the recognized mode of regional and metastatic infection of carcinoma, and is as unlike microbic infection as these other processes are admitted to be.

The "Tumour Germ". Theory-Cohnheim's Theory.

There is one theory which is more consistent than any other with all that we know about malignant diseases, which fully explains the origin of very many non-malignant tumours, and is, I believe, destined to be accepted as the true explanation of the genesis of malignant new growths. It is the theory which was put forth by Durante of Rome about the year 1874, and a year or two later by Cohnheim (1877)..

Cohnheim referred the origin of carcinoma to the proliferation not of mature but of embryonic epithelial cells. He taught that all tumours originate from a matrix of embryonic cells, which during fetal life are cut oft from their proper connexions, remain in an undeveloped state, are surrounded by developing and ultimately developed tissues, and thus become, so to speak, "embryonic inclusions." According to Cohnheim these groups of of cells, or "tumour germs" are portions of the germinal layers which, through not being utilized in the rrowth of the embryo, or by becoming displaced from their proper relations during the process of cell differentiation in the embryo, remain in a quiescent or latent state until excited into activity by one or other of several causes at some indefinite period after birth.

Cohnheim insisted that a tumour never had its origin directly or indirectly from mature tissue. And herein lies the rifference between Durante and Cohnheim for whilst the latter regarded the matrix of embryonic cells or "tumour srerm" as always of congenital origin, Durante thought that the elements from which arise all neoplasms, and especially the malignant, are either those "which preserve in the adult organism their embryonic anatomical characters, or which have acquired them again through weakening of their chemical and physiological activity."

Obviously Cohnheim's doctrine is insufficient by itself to explain the formation of malignant new growths in scar tissue, in immature callus, in unabsorbed inflammatory products, and in parts after injuries and operations of various kinds. This deficiency is met by extending the theory so as to include groups of cells which become isolated beyond their own natural boundaries by post-natal processes.

Nicoladoni in 1881, in a paper on epithelioma in sequestrated wounds (les plaies à séquestre) attributed the origin of the new growths to shreds of skin which had become displaced into fistulous tracts, and had there proliferated under the stimulus of an accidental inflammation of the part or of an operation.

Ribbert has indicated the possibility, during an inflammatory process, of a group of newly-formed epithelial cells becoming completely detached from their natural parent tissue, and of the cell or cells, so withdrawn from the control and growth-regulating influence of normally surrounding cells, assuming an exalted imdependence and power of proliferation, whereby a tumour becomes developed. He also recognizes that a fragment of sequestrated tissue detached by trauma of any sort may in the same way become a "tumour germ."

It was to meet this deficiency of the Cohnheim theory that Senn added to it this corollary: "The tumour matrix may be composed of embryonic cells, the offspring of mature cells, which have failed to undergo transformation into higher tissue, and which may remain in a latent, immature state for an indefinite period of time, to become, under heredity or acquired exciting causes, the essential starting-point of a tumour." Senn expresses this extension of the "tumour germ" theory, in his definition of a tumour, thus: "A tumnur is a localized increase of tissue, the product of tissue proliferation of embryonic cells, of congenital or post-natal origin produced independently of microbic cause."

We thus see how Durante, Nicoladoni, Ribbert, and Senn embrace and supplement the incomplete theory of Cohnheim by recognizing a post-natal origin of a cell matrix.

I propose now to examine separately, as well as the time will permit, the evidence in favour of the separate parts of the "tumour germ" theory, namely:

I. The existence of congenital matrices of embryonic cells.

2. The existence of matrices of post-natal formation. 3.

4. The causes which arouse the matrices into activity.

I. First, what proof do we possess of the existence of congenital matrices of embryonic cells? It is hardly necessary to enumerate the many instances of "vestiges" and "fetal rests", which are found in the human body, as they now form a brief chapter in the latest textbooks on anatomy. Tracts of embryonic epithelium are well known to occur in the tongue, gums, face, scalp, neck, brain, eye, testicle, broad ligament, ovary, and along the lines of coalescence of the trunk.

For many other instances of vestigial and abnormal structures reference may be made to Professor Arthur Robinson's article in Morris's Treatise on Anatomy.

Dr. J. Beard, in a lecture on Embryological Aspects and Etiology of Cancer, ${ }^{6}$ states that in elasmobranch fishesand he implies that the same conditions pertain in man-a considerable percentage of the primary germ cells fail to reach their normal position, the germinal ridge; that many of these vagrant germ cells degenerate and disappear, but all do not; and that the common situations for the origin of cancer are the very ones in which vagrant persistent germ cells are usually met with.

2. The occurrence of matrices of embryonic tissue of postratal origin is capable of completely satisfactory explanation. Leo Loeb ${ }^{7}$ has described how in the healing of a superficial wound the epithelium of the skin on either side of the wound was seen to have fused itself into a cell mass which sent off branches not only across the wound, but down into the blood clot and the connective tissue, especially if the connective tissue had been injured; and these branches of the cell mass even burrowed through cartilage. It is intelligible enough therefore how in the cicatrization of ulcers and wounds generally, some of the epithelial buds may become "isolated," and being thus shut off from their proper anatomical relations and from their normal function. may under suitable stimulation develop into carcinoma. Epithelial cells not utilized in 
the process of epidermization and becoming buried in the scar tissue may, when brought under the influence of the needful exciting cause, give rise to carcinoma. This sequestration of unused cells may occur after burns, chronic ulcers, lupoid and syphilitic sores, fissures, sinuses, fistulae, compound fractures, cracked lips, the excoriations from soot, tar, or paraffin, lacerations and ulcerations of the cervix uteri; and after the alternate breaking down and healing in such diseases as ichthyosis of the tongue, cheek, vulva, and vagina, or ulcers caused by carious teeth, as well as after wounds whether operation wounds or otherwise.

In like manner a matrix may be produced from which sarcoma may arise. In parts which have been the seat of chronic inflammation, and in scars. unspecialized connective tissue cells may be buried, and will be there ready to grow into a sarcoma under the influence of a sufficient exciting cause. Some of the embryonic cells during the process of repair of a fracture may fail to attain to the perfection of their parent cells, and will thus remain in the part in a latent condition like the congenital matrix of embryonic cells pre licated by the original theory of Cohnheim.

3. What proof have we that a matrix of embryonic tissue, whether of congenital or acquired origin, can remain for a length of time in a quiescent state, and then suddenly start into active growth under the influence of some stimulus ?

This is actually witnessed in the growth and development of the teeth, bones, the skin and its appendages, the larynx, the mamma, and the organs of generation, the cells of which remain for years in a state of incomplete differentiation, and then normally, under the physiological stimulus which occurs at puberty, take on rapid proliferation. Pathologically the same suddenly aroused activity is seen in certain epithelial tumours which are rarely noticed before puberty, such as dermoids, branchial cysts, and mammary adenomata. Rudimentary organs and accessory organs, which hitherto as to growth have been stationary as well as functionless, become the starting points of tumours, more especially at and after puberty.

4. The causes which arouse a matrix into action are numerous. For a matrix of embryonic cells to be transformed into a tumour it must be aroused into activity by some exciting agent. We must now inquire what these exciting agents are, and in what relation the commonly ascribed causes of cancer stand to the "matrix" or "tumour-germ" theory of cancer causation. The stimuli which arouse the cells of the dormant matrix to active proliferation are either general or local, congenital or acquired, and the chief amongst them are the alleged common causes of cancer just enumerated. Let us consider four of them in some detail, namely, heredity, age, traumatism, and chronic irritation :

4. (a) Heredity. - A case like that of Friedreich, where a woman with carcinoma gave birth to a child affected with carcinoma, is altogether exceptional. Statistics hitherto have given insufficient and inaccurate information concerning the frequency with which the offspring of parents carcinomatous at the moment of conception or delivery have been affected with carcinoma. There is, however, no more reason to doubt that un aptitude is transmitted from parent to child for the development of carcinoma and sarcoma than for denying an liereditary disposition to various other diseases. This aptitude, or predisposition to malignant disease, has been appropriately described as "a diminution of the physiological resistance of the tissues," which permits of their being invaded and destroyed by the proliferating cells of the tumour matrix. In the great majority of cases (in Cohnlieim's view, in all cases) the matrix itself is of congenital origin; but, though congenital, it may never be excited into activity. In others the matrix is of post-nutal origin; and if the necessary stimulus arises and the tissue resistance is weak, cancer will occur, even in persons in whose family cancer had hitherto been absent.

4. (b) Age.-There may be in the same person several congenital matrices, one or more of which may be of the epithelial type, one or more of the connective tissue kind. During chiildhood and young adult life the exciting cause, or matrix stimulus. will start into activity a connective tissue "tumour germ" ; but during mature life and in advanced age the same stimulus will arouse by preference a matrix of embryonic epithelial cells, because the epithelium is more active and vigorous than the connective tissue at the later periods of life.

Assuming the presence of a congenital matrix of each kind in the same individual, and that middle life has been reached without the occurrence of any matrix-arousing stimulus, but that after this period some general exciting cause comes into existence, the matrix of embryonic epithelial cells will most likely be the one to respond, and a carcinoma, not a sarcoma, will result. But there may be the simultaneous appearance of different kinds of tumours. Should the stimulus be a local not a general one, the matrix upon which alone it acts will be aroused, and a carcinoma or a sarcoma will be developed according to the type of cells forming the matrix which is stimulated.

With advancing age or senility of tissue come impaired vitality and lessened power to resist the effects of injury, hence the diminution of the physiological resistance of the tissues and the increased proneness to the formation of cancer. Little is known, it must be admitted, of what this "physiological resistance" really consists; what this power is which holds in check altogether, or for a long time, the proliferating tendency or force of a tumour matrix, as it does for years the growth and development of the mammary glands, the organs of generation, the teeth, the larynx, and the beard.

The existence of such a force was, however, demonstrated by Cohnheim and Maas, who introduced pieces of young periosteum into the jugular veins of animals. The periosteum produced bone which was always limited in size to the lumen of the vessel in which the periosteum embolus became impacted; the bone never extended beyond the vessel walls, a physiological resistance restricted it, no further growth ensued, and in time the ossified periosteal graft was absorbed. 'The same investigators showed that transplanted grafts of embryonal tissue succeed, whereas grafts of mature tissue are invariably removed by absorption in a short time.

Embryonic tissue - fetal cartilage, for example-taken from animals before the are born and engrafted into rabbits, proliferated abundantly; grafts from benign tumours only grew to a very limited extent, if at all, and were then removed by absorption.

Grafts of malignant tumours have almost without exception failed, though, composed as they are, of embryonic tissues. This seems to show that the physiological resistance to malignant cell proliferation is, happily, more effective than against fetal embryonic tissue, or against the embryonic tissue of benign tumours.

The weakness, or want, of this physiological resistance, besides being sometimes inherited, and often a consequence of age, can be acquired through injury, irritation, inflammation, and other pathological, general, or local causes.

4. (c) Traumatism is often said to cause malignant disease, just as it used to be said to cause inflammation and suppuration. But just as no amount of injury will of itself excite suppuration without the presence of pathogenic and p5ogenic organisms in the injured tissues, so no amount of injury will give rise to a tumour without the presence of a matrix of embryonic tissue of either congenital or post-natal origin. No so-ealled exciting cause will produce cancer or sarcoma in the absence of the "tumour germ" of epithelial cells or connective-tissue cells respectively. But given the presence of such a matrix, then injury of any kind, irritation of any kind - mechanical, chemical thermal, or : microbic-may excite cancer formation, both by arousing the matrix into activity and by diminishing the physiological resistance of the surruunding or adjacent tissues. Whether the cancer follows the injury quickly or tardily depends upon the intensity of its effects upon the matrix or upon the degree to which the physiological resistance or, what is probably the same thing, the nutrition is affected; or upon both these conditions.

4. (d) Prolonged irritation and inflammation may (1) excite a matrix of congenital tissue to proliferate ; (2) may diminish physiological resistance of the tissnes around it; or (3) may provide a post-natal matrix of embryonic epithelial or connective-tissue cells, and thus originate the essential factor of malignant disease, as well as stimulate it into proliferative activity.

Carcinoma of the breast following eczema of the nipple is an instance of malignant disease aroused by chronic irritation and inflammation. Epithelioma of the tongue following long-standing ichthyosis of that organ is another. They are typical illustrations of agents which act in each of the three ways' just mentioned. 'Yet that neither of these pathological ijritants is of itself the true and essential cause of carcinoma is proved by cases in my own practice. In 1880 I published two of the earliest reported cases of chronic eczema of the nipple (Paget's disease). Out of 305 cases of mammary diseases which up to that time I had seen in my hospital cancer out-patient practice, eczema of the nipple was met with in 
8 cases, in 6 of which there was no cancer present in the mainmae. In only 2 cases, then, out of 8 did carcinoma of the breast follow the chronic eczema of the nipple and areola. It is certain, therefore, that something more than the longstanding irritation of chronic eczema is needful for the development of mammary cancer, and this something is a "tumour matrix" in the breast. If due to irritation alone, why did not carcinoma occur in all the eight cases equally?

Iclithyosis of the mucous membrane affords similar proof against the sufficiency of chronic irritation per se to excite carcinoma. In 1883 I published a paper on ichthyosis and epithelioma of the tongue. In 13 out of 36 cases of epithelioma of the tongue ichthyosis oi the tongue had been a precursor of the carcinoma. In $I 1$ other cases of ichthyosis of the tongue and in 3 cases of ichthyosis of the buccal and labial mucous membrane ( 14 in all), carcinoma did not occur.

The inference from these cases also is that in the 13 cases in which carcinoma supervened there was in the corium or submucous structures a matrix of embryonic epithelial cells which was stimulated into malignant growth by the longstanding ichthyosis. In the 14 cases in which carcinoma did not supervene, the presumption is either that there was no matrix, or that the exciting cause was inadequate to arouse the matrix into activity, or that the physiological resistance of the surrounding tissue was sufficient to prevent its growth.

5. The validity of the premisses of the "tumour germ" or " inatrix" theory being assured, let us see whether the conclusion to which the theory leads can be established by actual facts. This conclusion is that cancerous as well as simple tumours spring from "inclusion masses," some of which are "displaced" masses, of embryonic cells either of congenital or post-natal origin.

5. (a) A large variety of benign tumours which are now known to arise from congenital matrices might be quoted.

5. (b) There is no lack of evidence, either, that tumours are formed from matrices of post-natal origin. We know that tumour germs arise as the outcome of surface epithelium, hair follicles, or portions of skin forced into the deeper tissues by punctured and other wounds. From such sequestrated fragments of tissue "implantation cysts" are formed -a group of small tumours allied in character to the sequestration dermoids derived from matrices of congenital origin. "These "implantation cysts" when occurring on the fingers are known as "digital dermoids." Others lollowing lacelated wounds have been met with on the scalp containing hair and sehaceous material.

Cysts of the iris following mechanical injury have been found to contain sebaceous matter, and in one recorded case an eyelash. Cysts lined with layers of cells like those on the anterior surface of the conjunctiva have been known to form in the cornea after gunshot and other accidental wounds, as well as after operations for cataract, and are almost certainly derived from conjunctival epithelium forced into the deeper lavers of the cornea.

5. (c) It has been unquestionably proved that the "tumour germ" theory correctly accounts for the origin of many varieties of benign solid tumours, and of dermoids and other cystic tumours; and.we must now try and answer the question with which we are especially concerned. Does it not afford the true explanation of the etiology of malignant tumours also? In attempting to reply to this question, it may first be pointed out that regions and organs in which embryonal inclusions are specially likely to occur are also common situations of primary malignant diseases. To realize the truth of this statement we have but to recall the frequency of sarcoma near the ends of long bones, the occurrence of myeloid and periosteal sarcoma and epithelioma in the mandible and upper jaw, of carcinoma of the uterus, resophagus, stomach, and rectum, tongue, and mouth. In the lip the commonest seat of origin of carcinoma is along the line of junction of the skin and mucous membrane. In the rectum the parts at or near the junction of the skin and mucous membrane, and those near the union of the proctodeum (cloaca) and the hind gut are the areas of the greatest liability to carcinoma.. In the stomach the pylorus and its immediate region are the chief seats of carcinoma ; and it is here, as Cohnheim has pointed out, that the anatomical structure of the organ varies most: it is here, also, that there is the greatest liability to pathologiçal changes, and thus to the development of post-natal as well as or congenita matrices. Such anatomical artas as those just mentioned like the cervix uteri are zanes of transitional epithelium and are provided with glands not always of normal functional perfection; in these so-called "cancer belts" we may expectantly look for "tumour germs" in the form of isolated congenital nests of embryonic cells.

In a thesis for the Doctorate of Toulouse in I902 Guillaume Cargue has written on the occurrence of epithelioma in the old sites of osteomyelitis. The author quotes 44 cases collected from literature, together with 5 cases observed in the clinic of Professor Jeannel, of Toulouse. In all these cases epithelioma of the bones was due to fragments of skin which became invaginated, or to detached epidermis cells which became implanted in the bones. The carcinoma appeared either in a diffuse form, or completely enclosed in the tissue of the bone.

Cargue referred to other cases of primary epithelioma of bones after fractures, or in connexion with necrosis. He also quotes from a communication on Tumours of Bone, made to the Congress of Surgery in 1899 by Polosson and Berard of Lyons to the effect that epithelioma occurring in the maxilla is always due to the proliferation of epithelial cells of the mucous membrane, which have become included in the bones with the dental germs. He refers also to Nicoladoni's work on the formation of epitheliomata in sequestration wounds. Several observers are mentioned by Cargue as having contributed to medical literature cases of epithelioma. which have developed in old scars, ulcers, callosities, fistulae, and such-like affections or the soft parts ; and he concludes that the same paucity as regards these as well as of similar recorded cases of primary epitheliomata in connexion with bones is due to surgeons not having recognized the real nature of the disease, or of having failed to ascertain the actual seat of it.

Various forms of malignant tumours of the kidney are attributed to fetal rests, such as adrenal inclusions and aberrant renal tubules, embedded in the capsule of the kidney, and which have been stimulated into epithelioma.

Dr. Charles Creighton has described malignant tumours as arising in and near the mammae, and in the axillae, from certain sweat glands situated under the skin, not usually in it, but between it and the axillary fascia. These sweat glands sometimes occur also along the lateral and anterior regions of the chest, and as appendages of the milk sinuses scattered through the mammae. They must be regarded as survivals or rudimentary organs, and as subject to all the risks of such survivals or rudiments.

Dr. Creighton also describes coiled tubular glands and a rudimentary mammary lobule consisting of a branched tube without real acini as being the starting-points of carcinoma within the mammary gland, and he considers that the proper mammary structure takes really no part in the morbid growths of the organ.

Volkmann described deep-seated primary carcinoma originating in the neck from the branchial clefts under the name of "carcinoma brancheogenes" and Guttmann refers to similar cases starting from accessory. thyroids as "struma carcinomatosa accessoria."

In the cases of multiple tumours in bones of the nature of thyroid tissue recorded by myself and others, the conclusion was : irresistible that the tumoturs were metastases from accessory thyroids, or from matrices or "inclusions" within the substance of the thyroid gland itself.

It is doubtless due to the fact that in these cases, as in some instances of carcinoma, the metastatic growths so far exceeded in size and conspicuousness the primary tumour that the nodule in the thyroid gland from which the tumour cells had migrated has been overlooked.

I. am indebted to Dr. Bashford for the details of a case recently published by von Oderfeld and Steinhaus which is: a confirmation of this opinion. A nodule slightly differing from the normal thyroid tissue and surrounded by a connective-tissue capsule was found in the right lobe of the thyroid of a female, forming a primary tumour from which metastases in, the cranial bones, the clavicle, and sternum were derived.

The pernicious growth of the ohorion, known as deciduom malignum, which occurs in the human uterus when the embryo is aborted, or dies before the asexual generation has been suppressed, was pointed out by Marchand in 1895 to be of a carcinomatous character, and is quoted by Beard ' $\alpha$ ' being " the key to the problem of the nature of cancer," and as making the cause of cancer as "clear a's the light of day."

The remnant of ovarian tissue occasionally left behind after an ovariotomy may become pathologically active, serve 'als a post-natal matrix, and develop into malignant diseade. 
Roger Williams ${ }^{8}$ attributes the great frequency of malignant disease which follows the removal of one or both ovariesand which in Spencer Wells's experience amounted to 36 per cent. of the known causes of death of those who had recovered from the operati in-to the excessive formative activity aroused after the operation in the aberrant accessory ovarian structures which are so frequently present in the broad ligament and its vicinity.

Primary carcinoma originating in a situation where no epithelium normally exists sometimes springs from a previously undetected dermoid cyst or dermoid cyst matrix. A displaced matrix of epithelial cells isolated from its own blastodermic tissue and buried in the mesoblast, if it becomes a tumour, will develop into one of an epithel:ai character. Tumour cells, like normal cells, always breed true. Connective-tissue cells cannot produce epithelial cells, and epithelial cells invariably produce their own kind and no other. Virchow when he met with a primary carcinoma in the tibia, not recognizing this physiological law, believed the cells of the carcinoma were produced from the connective tissue at the spot where he found them, and called them epithelioid. The knowledge of this law as applied to a carcinoma developed from a displaced or misplaced epiblastic matrix which had been roused into proliferative activity by some exciting agent corrects such a histological error, and explains the occurrence of the heterohlastic tumour. It also explains how an "endothelioma." which resembles carcinoma in its characters, is developed as a primary new growth in serous membranes and lymphatic glands-structures which are of mesoblastic origin, and in which, therefore, no epithelium normally exists; it likewise explains how a gliom?, which in its anatomical and clinical characters is a sarcoma, can occur in the brain or recina which are derived from the epiblast.

6. We must next inquire whether the "tumour germ" theory can account fur the transformation of a benign into a malignant new growth. We need not stop to inquire what evidence there is that this transformation takes place. The fact of its doing so is no longer, as formerly it was, disputed. Warts, moles, dermoids, fibromata of the skin, uterine myomata, and papillomata in various situations might be quoted in proof of benign tumours passing into malignant.

The change to malignancy may originate in a matrix of tissue derived from the organ or part affected, and which become sequestrated and enclosed within the structure of the benign tumour during the process of the growth of the tumour. Or in the process of the growth of the benign tumour some of the daughter cells may fail to attain the degree of differentiation of the parent cells, and may subsequently develop on their own account into a malignant neoplasm.

A woman under my care some years ago was the subject of an intramural uterine fibromyoma, which became the seat of colloid carcinoma. The case was published by Mr. Roger Williams, ${ }^{9}$ who mentions that a few cases of carcinoma originating in uterine fibroids had been recorded by. Virchow and others. It is probable that in my case the carcinoma, which was clearly glandular, was developed from the deep extremity of one of the utricular glands sequestrated in the process of the growth of the fibromyoma, and. which thus came to form an epithelial tumour germ-just as glandular elements have been observed in the analogous new growths of the prostate.

\section{Other Evidence in Favour of the "Tumour Germ" Theory.}

A.- The matrix theory escapes equally the objections raised against the local and the constitutional theories of cancer.

B.-The matrix theory enables us to understand the long intervals which occur after removal of cancer by operation before recurrence takes place ; for just as the " tamour germ", of the primary growth remained for years unaroused, so a single cell or a few. cells migrated to a lymph gland or duct, or into the areolar tissue some distance away, may continue quiescent owing to the efficiency of the physiological resistance of the surrounding tissue. The cell or cells are the "tumour germ" of the recurrent growth, as the original matrix was of the primary, and are subject to the same kind of restraint and respond to the same kind of stimuli.

C.-The "tumour germ" theory also explains the so-called reeurrences, after either short or very long intervals, in parts or organs away from: the original site, and out of the line of direct Iymphatic infection. It explains, too, the development in the same person at the same time of two tumours of dif- ferent blastodermic sources, or of another tumour forming after one of a different kind has been excised.

D.-Lastly, the "tumour germ" theory affords a better explanation of the local extension of carcinoma than any other which has been put forward. It ascribes it to cell proliferation of the margins of the matrix; the growth of the tumour to the multiplication of the matrix cells, not to the "reversion" or conversion of the pre-existing mature epithelium in to tumour tissue.

The foregoing are some of the reasons for regarding the "tumour-germ" theory as the most-indeed, in my opinion, as the only--probably correct theory of cancer origin which has ever been put forward, as the only hypothesis which is consistent with all the known facts of cancer.

Hitherto, so far as I can ascertain, what would seem to be the strongest evidence against this "tumour-germ" theory is that which seems the strongest evidence in favour of the microbic theory - namely, the successful serial experiments upon mice with cancer-tumour tissue, which were carried out by Morau in 1893 , and have been recently repeated by Jensen and Borrel. But Borrel admits that his successful series was only obtained by treating at pach passage a number of mice, varying from twelve to fifteen. This is of much importance, because many mice were found to be unaffected. The proportion of successes to the total number of animals experimented upon at each passage in the series ought to be given by each experimenter. The tendency to the development of cancer in mice would seem to be strong judging from what is stated in Borrel's paper as to the frequency of cancer in certain caged mice not operated upon.

Up to the present time the microbic theory has not. advanced our knowledge of the cause of cancer one iota, in spite of all the talent and skill which have been employed upon it ; whereas every year facts in support of the "tumourgerm " theory are discovered almost without being sought for. Excepting for these aforesaid recently discovered facts, our knowledge of the causation and nature of cancer would.be no greater now than it was thirty years ago ; indeed, the very facts about cancer which were recognized and established a generation ago are to-day the strongest a priori arguments against the probability of the microbic origin of cancerous diseases.

The truth is that for the last ten or fifteen years cancer research has been too exclusively directed to microbes, and too little to cancer. The attention given to cancer research by many able workers has been too restricted to the search for the problematical. "cancer organism" to allow of much thought being directed to the other factors in cancer. The "high power" lens, and the fine adjustment, so to speak have put into the background for the time being the binocular field glass with its adaptibility for focussing the various features of an extensive perspective. It is, however, well that all these bacteriological observations and experiments have been made; indeed, others are still necessary, if only to clear up certain difficulties respecting the nature of the so-called "cancer bodies," and how they come to be present in the cancer cells.

But what is wanted also is that some equally-skilled research work should be directed to other questionsembryological, morphological, chemical, and functional : to such subjects, for example, as those to which Marshalj drew attention in his suggestive Morton lecture-namely, the chemistry of cancer tissue the structure and changes in the stroma, the minute anatomical relation of nerves to the cancer cells, and of the effect of the loss of control of the nervies over them. We want more information respecting the state of the arteries in cancerous new growths. The arterial changes in cancer tumours have not so far been sufficiently studied. They may, however, prove to be of importance in connexion with treatment; with the clinjcal effects and histological results of the $x$ rays upon cancers; and also in relation to the rate of growth and the tendency to metastasis by various degenerations, and to ulceration and sloughing of cancerous tumours.

All questions of this kind may be worked out in private or hospital laboratories; but there are numerous other important questions to be answered-for example, as to the agencies which excite into action the invariable and unconditional cause of cancer. These never yet have been properly investigated, and they can only be so by some such organized scheme as that which has recently been undertaken by the two Royal Colleges. Questions as to the geographical and racial distribution of cancer, of climate, soil , articles of diet 
occupations, cancer houses, and many others can only be settled after statistical and other investigations have been made and checked and cross-checked, controlled and recontrolled by each other. Such investigations are beyond the means and powers of individual science workers or of medical institutions, and need to be undertaken by an organized body with relays of workers and sufficient funds at its command to provide for the uninterrupted pursuit of the inquiries.

Katz, of Hamburg, whom I have previously quoted, remarked: "It is to be deplored that Cohnheim's doctrine has so long found an extended acceptance, for the further development of cancer research would have, through it, no value. A standstill would result from the fatalism which underlies this theory. The same may be said with regard to Ribbert's theory, which, though of far later date than Cohnheim's, is in pursuit and continuation of it:"

But a theory, if it has the evidence of truth, must be minutely and impartially examined, even though it seems to lead to a conclusion which we might wish to escape. There is, however, no occasion for so pessimistic a view as that of Katz. The "tumour-germ" theory, at least does this : it convinces us of the local origin of cancer, and of the positive curability of it if removed quite early and completely. Of course, it does not guarantee one against the formation of another malignant new growth, any more than the repair of a broken bone guarantees one against the occurrence of another fracture. It should also encourage the early and more frequent removal even of benign growths. Future researches may reveal a method whereby a special inhibitory influence may be brought to bear upon the cells of the "tumour matrix," on the lines tried by Foulerton; or a restraining, even a strangulating, effect upon the tumour cells by the tumour matrix may be produced, as suggested by Marshall. But in any case, we can reasonably hope and expect that the organized researches now commenced by the Colleges will in time yield much information as to how to prevent cancer by teaching us what are the real agencies which stimulate it into existence.

In bringing these remarks to a conclusion I will borrow the description recently given by Mrs. Crawford of the mind of the late M. Thiers, and apply it to the theory founded by Durante and Cohnheim. "It has search-light luminosity. Like radium, it keeps burning brightly, without consuming itself." And, I would add, it will not only remain active and brilliant to the end, but it will, I believe, shed more and more light on the etiology of cancer with every fresh addition made to the science of embryology and to our knowledge of tumours.

1 Arch. Gén. ReFERENCES.

3 Arch, de Méd. Méd., June, I892. ${ }^{2}$ Sem. Med., September 24th, rgoz. Ceritralb. f. Bakt., June, roo3. ${ }^{4}$ Ann. de linst. Pasteur, January, 1903. Bulletin, January, 1898. 8 Lancet, November 14 th (p. 1393) and 28 th (p. 1530), 903. ' Path. Soc. Trans., 1886, vol. XXxvii, p. 354.

\section{THE PARASITIC THEORY OF CANCER.}

\section{BY H. (x. PLIMMER, F.L.S.,}

In charge of the Cancer Laboratories, Lister Institute of Preventive Medicine, and Cancer Hospital, Brompton.

Few things, even in medicine, have ever been so tangled as the views which are held by different people on the origin and cause of cancer, and few subjects have suffered so much from extremes of opinion, from no parasites to all parasites. The too hasty and too certain views of many workers (some of them founded on the examination of only one case) have made the thinking heads in our profession very shy of theories, and the critics work easy, or apparently so. But the battle around cancer still rages. Is it parasitic or not parasitic? The parasitic theory is by no means yet extinct, although some would have us believe so, especially those who are more willing, as are many, to talk about cancer than to work at it. I shall try to give some reasons why I think we dare not at present give up the parasitic theory of cancer, and I shall try to show that this theory is rot founded entirely upon speculations, but that it has sprung really from wider clinical and biological considerations of the subject.

The idea that cancer is an infectious disease is an old one: so long ago as i 797 it was classed amongst infectious diseases by the Prussian sanitary laws. But the question only came actually into practical pathology after the development of bacteriology: then the differences between cancer and the other bacterial infectious diseases gave rise to the view (after a very short-lived cancer bacillus) that it may be due to an organism of another kind, one on the animal side-a protozoon-and to this view Metchnikoff gave his support.

In reviewing the present position of this question I shall first consider it from the more general points of view, and shall then proceed to a more special examination of cancer itself, so far as concerns the present subject.

There can be no doubt that during the last few years there has been a considerable increase in the number of cases of cancer, and this increase is out of all proportion to any known general cause except a parasite. There are also on record many instances of relative increase in the frequency of cancer, which may be called epidemics of cancer, and it is very difficult to see why there should be such increase if the etiological factor were a constant one, but these epidemics are easily explainable from the parasitic point of view. The facts that the death-rate from cancer is in many districts $a b$ normally high, and that it varies greatly in the same district at different times, so that, as in other epidemics, a sudden increase in the number of cases occurs in certain years, seem only able to be explained by the presence of a parasite, which in certain places and times finds better conditions of existence for itself

Again, the disease has been shown to have a predilection for low-lying, damp districts, and especially for districts which have both wood and water; and of late years a number of observers, both here and abroad, have brought forward a quantity of facts showing its incidence in certain houses"cancer houses" they are even called-all of which points most urgently towards a parasitic origin.

Behla, who lived for a great number of years in Luckau, has made a most careful study of the occurrence of cancer in the various parts and houses of the town and its suburbs; and he showed that in certain parts the incidence was extremely high, and that in other districts there was none. The history is so remarkable, and I think so important as evidence for the parasitic theory, that I will briefly re-tell it. Luckau is a town with 5,000 inhabitants, 3,000 being housed in the central part, or town proper, and 1,000 in each of the two suburbs which flank it east and west. The population is agricultural, and during the years from 1875 to 1898 remained the same in number; their habits and ways of lile also remained unchanged. Between these years the deaths from cancer numbered I out of $25-30$ for the entire town; I out of 9 for the eastern suburb; and in the western suburb there was not a single case. The houses were similar in size and arrangements, and were, as a rule, damp. The soil of the main town and eastern suburb was moist, and lay low; that of the western suburb was, on the contrary, sandy, dry, and elevated. There was a large ditch which encircled the central town and the eastern suburb, not touching the western suburb, and the cancer followed closely the course of this ditch; the cases in the main town occurred chiefly in those houses whose gardens bordered on the ditch, and in the eastern suburb all the gardens were watered from the ditch. There were 127 houses in this quarter, and 56 of these were cancer houses, 43 with I case each, 10 with 2 cases, 2 with 3 cases, and I with 4 cases. The ditch contained foul stagnant water with which the people watered and washed their vegetables many of which were eaten raw. In Behla's opinion the probable source of infection-for such he considers it must be -was in the uncooked vegetables; and in this connexion I may mention the case of a very distinguished patholngist who, for the same reason, gave up eating salad and uncooked vegetables to my knowledge more than ten years ago. The figures of the city of Buffalo are also very striking with regard to this point. Dr. Lyon, in studying the cancer statistics of Buffalo for a period of twenty years, found that, roughly, for the same population, the cases of cancer in the German wards of the city were double the number of those in the native wards, and he mentions the fact that the Germans usually grew some vegetables, and were in the constant habit of eating many of them uncooked.

Apart from the question of uncooked vegetables, these figures are striking enough, and it is much to be hoped that more inquiries similar to Rehla's will be nndertaken elsewhere, with the care and intelligence which characterize his work.

How can we explain this occurrence in certain regions? How can we explain the increase of cancer at the present time? Is it that Nature does not now do her work so well as she did formerly, and that there are now more people than 